\title{
O PROCESSO DE LICENCIAMENTO AMBIENTAL NO PROJETO DE EMPREENDIMENTOS INDUSTRIAIS DE MINERAÇÃO
}

\author{
ENVIRONMENTAL LICENSING PROCESS IN INDUSTRIAL \\ MINING PROJECT
}

\section{Priscilla Meireles de Oliveira', Paulo Roberto Pereira Andery'}

RESUMO: Os projetos de mineração geralmente apresentam certa complexidade, e com frequência têm problemas de desempenho associados ao aumento de prazos para entrada em operação. Nesse sentido, um dos grandes gargalos, considerados caminho crítico nos cronogramas de projetos de mineração, é o licenciamento ambiental. Os processos de licenciamento ambiental têm se tornado cada vez mais rigorosos, com órgãos responsáveis mais exigentes, o que tem demandado um prazo significativo nos cronogramas dos projetos, acarretando muitas vezes impactos consideráveis na implantação dos empreendimentos. Nesse contexto, este trabalho apresenta um estudo exploratório realizado no estado de Minas Gerais, com o objetivo de fazer um levantamento da dimensão dos atrasos em licenciamentos ambientais e das suas causas. Dessa forma, pode contribuir para que, em futuros trabalhos, sejam propostas diretrizes para modificação dos processos de licenciamento, no âmbito da concepção e desenvolvimento dos empreendimentos. O estudo exploratório teve como base de análise os documentos constantes em 355 processos de licenciamento ambiental de quatorze empresas de mineração, formalizados no órgão licenciador mineiro. Foi constatado que um número substancial de empreendimentos tem prazos para a obtenção de licenças bem superiores aos previstos na legislação ambiental, impactando os cronogramas dos projetos. Constatouse, também, a alta incidência de solicitação de informações complementares por parte do órgão competente. Parte significativa dessas solicitações é decorrente de falhas na caracterização dos empreendimentos e das soluções de engenharia, bem como da falta de maturidade na análise do impacto ambiental e suas medidas mitigadoras. O trabalho é relevante na medida em que o conhecimento dos prazos praticados e das causas de atraso na obtenção de licenças ambientais permite aos empreendedores o estabelecimento de cronogramas mais realistas para a concessão das licenças, bem como o direcionamento de ações no sentido de evitar que estas solicitações ocorram, antevendo riscos e contribuindo para agilizar a análise dos processos de licenciamento.

PALAVRAS-CHAVE: Gerenciamento de Projetos; Mineração; Licenciamento Ambiental.

ABSTRACT: Mining projects usually feature some complexity, and often have performance problems associated with increased lead times. In this sense, one of the major bottlenecks, considered as a critical path in the mining project schedules, is environmental licensing. Environmental licensing processes have become increasingly rigorous, with more demanding bodies, requiring a significant period in the project schedules, often leading to considerable impacts on the projects' implementation. In this context, this work presents an exploratory study carried out in the state of Minas Gerais, Brazil, with the objective of surveying the extent of delays in environmental licensing and its causes. In this way, it can contribute to future works in order to propose guidelines to modify licensing processes, regarding project design and development. The exploratory study was based on analysis of the documents contained in 355 environmental licensing processes of fourteen mining companies, formalized with the Minas Gerais licensing body. The results point out that a substantial number of projects have deadlines for obtaining licenses that are much higher than those foreseen in environmental legislation, impacting project schedules. It was also verified a high incidence of request of complementary information on the part of the licensing authorities. Significant part of these requests is due to failures in the characterization of the projects and engineering solutions development. Lack of maturity

\section{How to cite this article:}

OLIVEIRA, P. M.; ANDERY, P. R. P. O processo de licenciamento ambiental no projeto de empreendimentos industriais de mineração. Gestão e Tecnologia de Projetos, São Carlos, v. 12, n. 2, p. 135-150. 2017. http://dx.doi.org/10.11606/gtp. v12i2.111519

Fonte de financiamento: Declaram não haver Conflito de interesse: Declaram não haver Submetido em: 28/02/2016 Aceito em: 04/09/2017 
in the analysis of the environmental impact and its mitigating measures also is an important factor. The work is relevant since the knowledge of deadlines and causes of delay in obtaining environmental licenses allow project sponsors to establish more realistic schedules for the granting of licenses, as well as to drive actions to prevent these requests from occurring, anticipating risks and contributing to streamline the analysis of licensing processes.

KEYWORDS: Project Management; Mining; Environmental Licensing.

\section{INTRODUÇÃo}

A literatura recente tem apontado para o fato de que, em empreendimentos complexos, como é o caso de projetos de mineração, são fundamentais cuidadoso planejamento e gestão fortemente focada nas interfaces e interdependências de atividades, os quais possibilitem maximizar o desempenho desses projetos em prazo, custo e qualidade (YUGUE; MAXIMIANO, 2013). Nesse sentido, uma das características dessa complexidade é a existência de elevado número de variáveis interagindo, e da elevada incerteza em seus comportamentos (VAN GUSTEREN; VAN LOON, 2006).

Independentemente da metodologia de gestão adotada, com frequência gestores de projetos se deparam com a chamada "tripla restrição", composta pelas varáveis custo, escopo e tempo do projeto. O gerenciamento de custos é fundamental para garantir que o projeto seja concluído em conformidade com o orçamento previsto e aprovado. Um escopo mal definido (que geralmente implica mudanças e alterações de projeto posteriores) ocasiona impactos significativos no tempo e custo do projeto (KARNA; JUNNONEN, 2017).

Um dos problemas críticos em termos de desempenho de projetos diz respeito aos prazos de execução, que, com frequência, são dilatados em função de uma multiplicidade de causas, nas quais se incluem falhas no processo de concepção e análise do ambiente do projeto (SANTOS; STARLING; ANDERY, 2015). Essa constatação, reportada na literatura recente, está em sintonia com observações realizadas por agentes do mercado. A título de exemplo, segundo o estudo de Benchmarking em Gerenciamento de Projetos Brasil 2010 (PROJECT MANAGEMENT INSTITUTE, 2010), o descumprimento de prazos é fator crítico de projetos industriais brasileiros.

Nesse contexto, o licenciamento ambiental pode ser considerado um fator de importância no planejamento e na implantação de projetos de mineração no Brasil. É frequente a ocorrência de atrasos nos cronogramas em função de planejamento de prazos subestimados para essa atividade, que já é tratada como caminho crítico nos projetos. Por sua vez, os requisitos para o licenciamento, estipulados por agentes governamentais e pela sociedade, com frequência não são devidamente captados ou são negligenciados (PIAGENTINI; FAVARETO, 2014).

Com o tema sustentabilidade cada vez mais em voga, os processos de licenciamento ambiental têm se tornado cada vez mais rigorosos, com órgãos licenciadores mais exigentes e sociedade e entidades fiscalizadoras mais atuantes, o que tem demandado um prazo significativo nos cronogramas dos projetos, acarretando, muitas vezes, impactos consideráveis na implantação dos empreendimentos.

Nesse contexto, este trabalho pretende apresentar um estudo exploratório para a identificação da dimensão dos atrasos nos processos de licenciamento ambiental de projetos de mineração, com a identificação das suas causas, obtidas a partir das evidências obtidas nos registros de processos de licenciamento. Este estudo permitirá, em trabalhos futuros, identificar possíveis diretrizes aplicadas aos processos de concepção dos empreendimentos, desde os estudos iniciais de viabilidade e considerando as distintas fases de seu ciclo de vida. Dessa forma, este artigo descreve 
os resultados da pesquisa relacionada à análise documental de 355 processos de licenciamento de quatorze diferentes empresas do segmento de minério de ferro.

Optou-se por realizar o estudo com foco no estado de Minas Gerais, tendo em vista que o estado possui inclinação para a mineração e que uma pesquisa realizada de forma global poderia não ser considerada representativa, já que devem ser tratadas as peculiaridades do licenciamento ambiental nos diversos estados brasileiros em função das especificidades das agências licenciadoras e das legislações que norteiam o tema.

Na sequência, o referencial teórico utilizado no trabalho é sinteticamente caracterizado.

\section{BREVE REFERENCIAL BIBLIOGRÁFICO TEÓRICO}

Embora a definição de complexidade em projetos ainda esteja em discussão, com base na literatura existente (YUGUE; MAXIMIANO, 2013), alguns elementos podem determinar o quão complexo é um projeto, tais como: multiplicidade de variáveis com elevado grau de interação; alto número de stakeholders; necessidade de utilização de tecnologias inovadoras ou específicas; alto nível de incertezas; comportamento e relação causaefeito imprevisíveis (BROCKMANN; KAIKONEN, 2012). Todos esses fatores associados produzem desafios frequentes e riscos emergentes, inerentes aos projetos caracterizados como complexos, demandando métodos, técnicas e habilidades específicas para a gestão do projeto. Essa complexidade exige, por um lado, que sejam revistos mecanismos e modelos de referência para a gestão da fase de concepção dos projetos, com ênfase em estruturas mais colaborativas de trabalho. Por outro lado, a ambiência do projeto e de seus condicionantes precisa ser bem conhecida, e tratada de formas diferentes ao longo do desenvolvimento dos projetos (VAN GUSTEREN; VAN LOON, 2006). Esse é frequentemente o caso dos projetos de mineração e seus condicionantes, como as questões ambientais, tratadas neste trabalho.

Do ponto de vista de agentes de mercado, segundo o estudo de Benchmarking em Gerenciamento de Projetos Brasil 2010, realizado pelo Project Management Institute (PMI), o problema que ocorre com maior frequência nos projetos das organizações públicas e privadas pesquisadas no Brasil é o não cumprimento dos prazos estabelecidos para os projetos, apontado por 60,2\% das organizações participantes (PROJECT MANAGEMENT INSTITUTE, 2010). Os outros problemas mais frequentes estão associados ao gerenciamento de escopo (mudanças de escopo constantes e escopo não definido adequadamente), comunicação e custos (TERRIBILI FILHO, 2013). Essa visão de mercado é corroborada por diversos estudos recentes sobre o desempenho dos projetos em relação a atrasos nos prazos de execução, que apontam ser este um fator crítico em grande número de projetos públicos e privados, tanto em países emergentes como desenvolvidos (AL-MOMANI, 2000; DOLOI et al., 2012).

Segundo Terribili Filho (2011), um dos oito grupos de causas potenciais de atrasos em projetos são prazos mal estimados devido ao excesso de otimismo ou ao desconhecimento das reais circunstâncias do ambiente de projeto. Nesse contexto, Pegoraro, Saurin e Paula (2010) afirmam que os principais marcos do processo de projeto estão ligados ao licenciamento ambiental, pois algumas ações dependem da liberação das licenças.

$\mathrm{O}$ atraso na obtenção das licenças ambientais também pode ocasionar prejuízos financeiros significativos aos projetos. Segundo Schmaltz (2014), os atrasos na obtenção da licença ambiental reduzem os valores de Valor Presente Líquido (VPL) para projetos de minério de ferro, tendo sido constatada em seu trabalho a redução de $11 \%$ no VPL por um ano de atraso, $20 \%$ por dois anos, $29 \%$ por três anos, $36 \%$ por quatro anos e $43 \%$ de redução no VPL por cinco anos de atraso. 
Segundo Moraes (2010, p. 134), “o grande gap dos projetos, hoje, no Brasil e mundo passa pelo licenciamento ambiental”, sendo considerado este o caminho crítico da fase de desenvolvimento de um projeto, juntamente com a elaboração dos estudos e relatórios que compõem esse processo. O licenciamento ambiental geralmente leva mais tempo do que o previsto pela legislação - atrasos podem variar entre meses e anos. O melhor caminho para minimizar esses atrasos é definir, a partir do planejamento ambiental estratégico, uma concepção de projeto na qual sejam esgotadas todas as opções em alternativas locacionais para estruturas de mineração (SCHMALTZ, 2014).

Melo (2014) relata que o licenciamento ambiental deve ser considerado como atividade crítica e que os prazos extensos para esse processo requerem que os documentos específicos para protocolos sejam priorizados. Tratandose especificamente de projetos de mineração, Silva Neto (2011) ressalta que a gestão ambiental, com destaque para a obtenção das licenças, representa o caminho crítico da maioria desses projetos.

Cohen, Adolfson e Wolfe (2011) afirmam que o primeiro passo no desenvolvimento de uma estratégia de licenciamento é identificar os recursos existentes e seus potenciais impactos e indicar os órgãos e jurisdições que regulam tais recursos, capturando esses elementos em um plano de aquisição de licença. $\mathrm{O}$ conhecimento precoce desses fatores e o desenvolvimento da identificação de licenças e do plano de aquisição pode ser elemento-chave para o sucesso do projeto.

Moreira, Silva e Palma (2010) demonstraram em sua pesquisa que uma mudança de escopo implicou atrasos nas atividades relacionadas aos procedimentos para o licenciamento ambiental e a emissão dos relatórios para encaminhamento ao órgão ambiental competente.

O licenciamento ambiental pode ser um complexo, demorado e caro componente para o planejamento do projeto. O conhecimento dos vários recursos disponíveis e dos regulamentos estabelecidos pelas agências e governos responsáveis pelo licenciamento pode levar a uma estratégia de aquisições de licenças que irá reduzir os riscos de cronograma e orçamento (COHEN; ADOLFSON; WOLFE, 2011).

Moraes (2010) sugere que, por meio da análise dos licenciamentos ambientais de projetos anteriores (incluindo seus respectivos documentos, estudos e relatórios) e entrevistas com a equipe de meio ambiente responsável pelos licenciamentos, poderá ser observado o tempo que foi necessário para obtenção das licenças para a implantação dos empreendimentos.

No estudo de caso desenvolvido por Pegoraro, Saurin e Paula (2010), a grande quantidade de requisitos legais e a legislação aplicável desencadearam um licenciamento ambiental longo, burocrático e que acarretou inúmeros retrabalhos para as equipes envolvidas no projeto.

Alguns problemas enfrentados no processo de licenciamento ambiental foram amplamente destacados por Schmaltz (2014). Entre os pontos abordados, podem citar-se:

a) prazos do licenciamento ambiental que extrapolam as normas legais;

b) novos requisitos/solicitações durante o processo de licenciamento de um projeto;

c) atrasos na emissão de autorizações para supressão de vegetação;

d) solicitações de outros órgãos reguladores que suspendem/atrasam o andamento do licenciamento;

e) subjetividade na determinação da compensação ambiental, já que não há norma legal para definição de todas as compensações devidas, ocasionando imprevisibilidade a tal questão;

f) baixa qualidade dos estudos ambientais elaborados e encaminhados ao órgão licenciador, com vários pedidos de informações adicionais pelos órgãos ambientais;

g) quantidade de páginas desnecessárias nos estudos ambientais; 
h) imaturidade e falhas no projeto de engenharia, que comprometem a preparação dos documentos ambientais que subsidiam o processo de licenciamento;

i) modificações nas soluções dos projetos de arquitetura e engenharia do empreendimento, implicando revisões dos documentos ambientais;

j) falta de qualificação dos técnicos responsáveis pela leitura e análise dos processos;

k) escassez de técnicos nos órgãos ambientais;

l) influência de fatores políticos ou ideológicos nas análises dos processos de licenciamento ambiental;

m)aumento crescente dos padrões de exigência técnica, que vêm se tornando cada vez mais rigorosos e restritivos.

As incertezas e imperfeições dos estudos de impacto ambiental, associadas a problemas relativos ao rito decisório - como a precariedade de formas de participação social ou os conflitos de interesses entre os stakeholders envolvidos no ritual do licenciamento -, fazem com que esses processos sejam marcados por morosidade, altos custos de transação e alto grau de contestabilidade social (PIAGENTINI; FAVARETO, 2014).

Soma-se a isso o fato de que a pressão para aprovação dos investimentos e início da implementação dos projetos, bem como a falta de integração entre as distintas disciplinas consideradas na fase de concepção dos empreendimentos, induz a se conviver com um baixo nível de maturidade (ou nível de completude) das soluções associadas aos projetos de engenharia e processos de licenciamento, o que propaga ou eleva o risco ao longo das fases subsequentes do projeto (ROSTAMI et al., 2015).

Nessa linha de raciocínio, Anantatmula (2015) relacionou o nível de indefinição das soluções de projeto, o que implica maior risco, com as falhas no desempenho do projeto, em termos de custo, prazo de entrega e qualidade dos produtos gerados. Karna e Junnonen (2017) identificaram que problemas de coordenação e compatibilização de informações entre disciplinas de projeto são fatores críticos no próprio atraso dessas disciplinas, raciocínio que se poderia aplicar à questão do licenciamento ambiental.

No que diz respeito ao objeto específico desta pesquisa, há ainda poucos trabalhos na literatura apontando problemas associados ao licenciamento ambiental em projetos de mineração. Prado Filho e Souza (2004) afirmaram que a previsão das questões de licenciamento ambiental nos empreendimentos de mineração e o impacto ambiental da operação desses empreendimentos incorporaram-se de maneira definitiva às práticas gerenciais das grandes empresas do setor. No entanto, o dinamismo dessas atividades de operação implica a necessidade de revisão frequente dos critérios usados para a realização dos estudos ambientais e, mais ainda, a proposição de medidas mitigadoras para tais critérios.

No que se refere à indústria de mineração, além do processo formal de licenciamento ambiental, é amplamente reconhecido que o principal problema em nível internacional é uma constante e crescente percepção negativa da sociedade com relação à atividade minerária (EVANGELINOS; OKU, 2006).

Para melhor compreender os processos de licenciamento, observa-se que a legislação brasileira prevê as seguintes modalidades de licenças, conforme a Resolução Conama $n^{0}$ 237/1997 (BRASIL, 1997): a) Licença Prévia (LP), aprovando a localização e concepção do empreendimento, atestando a viabilidade ambiental e estabelecendo os requisitos básicos e condicionantes a serem atendidos nas próximas fases de sua implementação; b) Licença de Instalação (LI), que autoriza a instalação do empreendimento ou atividade de acordo com as especificações constantes dos planos, programas e projetos aprovados, incluindo as medidas de controle ambiental e demais condicionantes; e c) Licença de Operação 
(LO), que autoriza o início da operação da atividade ou empreendimento, após a verificação do efetivo cumprimento do que consta das licenças anteriores, com as medidas de controle ambiental e condicionantes determinados para a operação.

\section{MÉTODO DE PESQUISA}

Uma vez que o objetivo da pesquisa foi identificar o nível de atrasos e possíveis causas nos licenciamentos ambientais de projetos de mineração, como um primeiro passo para compreensão do problema realizou-se um estudo exploratório, nos moldes propostos por YIN (2013). Esse diagnóstico permitirá que, em trabalhos futuros, sejam estabelecidas diretrizes para a melhor gestão dos processos de licenciamento ambiental.

A principal fonte de evidências foi o banco de dados do órgão responsável em Minas Gerais pelos licenciamentos ambientais no estado, por meio de consultas a documentos físicos e eletrônicos dos processos de licenciamento ambiental do segmento de mineração.

Para a seleção dos processos de licenciamento, objeto deste trabalho, realizaram-se pesquisas por nome das principais empresas de mineração de ferro atuantes no Quadrilátero Ferrífero e pelas atividades associadas a essa tipologia, cujos processos de licenciamento foram formalizados a partir de 2004, considerando as seguintes modalidades: Licença Prévia (LP), Licença de Instalação (LI), Licença Prévia concomitante com a Licença de Instalação (LP+LI) e Licença de Operação (LO).

Para todos os processos de licenciamento, as informações coletadas foram as seguintes: tipo de processo de licenciamento formalizado; tipo de estudo ambiental apresentado para a formalização do processo de licenciamento; data de formalização do processo de licenciamento; data de concessão da licença; status atual do processo; solicitação ou não de Audiência Pública; informações complementares solicitadas, entre outras. Esse mapeamento foi realizado no período de janeiro de 2014 a agosto de 2015.

De posse das informações coletadas, realizou-se uma análise quantitativa e qualitativa quanto aos processos de licenciamento ambiental, visando identificar prazos praticados para obtenção dos diversos tipos de licença e analisar os fatores/exigências dos órgãos ambientais que ocasionaram atrasos nos processos de licenciamento.

A partir dos dados levantados, as causas registradas de atraso, em especial dos decorrentes de solicitações de informações adicionais, foram estratificadas em categorias, permitindo uma análise por tipo de problema. A estratificação foi feita a partir da análise dos registros de causas das solicitações de informações adicionais, agrupadas por semelhança. Essa estratificação passa a ser uma contribuição do trabalho, na medida em que organiza em categorias essas causas de atrasos, fornecendo informações que podem subsidiar futuros levantamentos e pesquisas.

\section{RESULTADOS E DISCUSSÃO}

Foram mapeados 355 processos de licenciamento de quatorze empresas de atuação no segmento de minério de ferro, situadas em 25 municípios do estado de Minas Gerais. Associadas a esses processos de licenciamento, foram catalogadas 972 informações complementares solicitadas por parte do órgão ambiental, ou seja, informações consideradas faltantes nos estudos ambientais protocolados pelas empresas, necessárias para a continuidade das análises dos respectivos processos de licenciamento.

A distribuição dos processos de licenciamento e informações complementares mapeados por modalidade de licença está apresentada na Tabela 1. 
Tabela 1: Distribuição dos processos de licenciamento e informações complementares mapeados por modalidade de licença

\begin{tabular}{l|c|c|}
\hline \multicolumn{1}{|c|}{ Modalidade de licença } & $\begin{array}{c}\text { № de processos de } \\
\text { licenciamento }\end{array}$ & $\begin{array}{c}\text { № de informações } \\
\text { complementares }\end{array}$ \\
\hline $\begin{array}{l}\text { Licença Prévia (LP) } \\
\text { Licença de Instalação (LI) }\end{array}$ & 29 & 160 \\
Licença Prévia concomitante a Licença & 104 & 306 \\
de Instalação (LP+LI) & 66 & 243 \\
Licença de Operação (LO) & 156 & 263 \\
Total & 355 & $\mathbf{9 7 2}$ \\
\hline
\end{tabular}

Fonte: Elaborado pela autora a partir das informações extraídas dos processos de licenciamento ambiental pesquisados

Com base nos levantamentos realizados, verificou-se que os prazos médios para obtenção das licenças ambientais são geralmente superiores aos prazos previstos na legislação ambiental vigente. A Tabela 2 apresenta esses prazos médios comparando-os com os prazos estimados legalmente, conforme previsto na Resolução Conama nº 237/1997 (BRASIL, 1997).

Tabela 2: Prazos médios e prazos legais para obtenção de licenças ambientais

\begin{tabular}{lccc|}
\hline \multicolumn{1}{|c|}{ Tipo de licença } & $\begin{array}{c}\text { Prazo médio } \\
\text { (em dias) }\end{array}$ & $\begin{array}{c}\text { Prazo legal } \\
\text { (em dias) }\end{array}$ \\
\hline Licença Prévia (LP) & 517 & $365^{*}$ \\
$\begin{array}{l}\text { Licença de Instalação (LI) } \\
\text { Licença Prévia concomitante a Licença }\end{array}$ & 374 & 180 \\
de Instalação (LP+LI) & 467 & 180 ou $365^{* *}$ \\
Licença de Operação (LO) & 398 & 180 \\
\hline
\end{tabular}

Fonte: Elaborado pela autora com base nas informações extraídas dos processos de licenciamento ambiental pesquisados

$\left(^{*}\right)$ Quando vinculados à apresentação de EIA/Rima.

(**) Variável de acordo com o tipo de estudo apresentado: Relatório de Controle Ambiental (RCA)/Plano de Controle Ambiental (PCA) ou Estudo de Impacto Ambiental (EIA)/Relatório de Impacto no Meio Ambiente (Rima), respectivamente.

Analisando-se esses dados, pode-se verificar que os prazos médios de análise são muito superiores aos previstos na legislação: $42 \%$ maiores para os processos de LP, $108 \%$ maiores para os processos de LI, 28\% maiores para os processos de LP+LI (considerando-se a apresentação de EIA/Rima, ou seja, 365 dias para análise) e, para os processos de LO, os prazos praticados podem ultrapassar em $121 \%$ o estabelecido na legislação.

Diante desse cenário, em função dos agentes intervenientes - órgão público e empresa solicitante-, podem ser levantadas algumas possibilidades para os longos períodos de análise dos processos de licenciamento ambiental. Essas possibilidades deverão ser verificadas a partir de outros levantamentos futuros. São elas:

- o corpo técnico é insuficiente ou o órgão ambiental está sobrecarregado, tendo em vista a intensificação das demandas por processos de licenciamento ao longo dos anos, ocasionando um acúmulo de processos para análise, fazendo com que o órgão ambiental não consiga acompanhar no mesmo ritmo a análise e concessão das licenças;

- a crescente preocupação com o conceito de desenvolvimento sustentável, ocasionando um constante aumento nos requisitos legais e no nível de exigência dos órgãos ambientais e a consequente 
necessidade de elaboração de estudos ambientais cada vez mais detalhados e minuciosos, demandando tempo e dedicação maiores por parte das equipes técnicas que analisam os processos de licenciamento, sem que essas atividades tenham sido previstas no escopo dos trabalhos;

- há falhas na formalização dos processos de licenciamento por parte dos empreendedores, fazendo com que as informações apresentadas ao órgão ambiental sejam consideradas insuficientes e demandem a solicitação de informações complementares para subsidiar a continuidade da análise dos processos.

As duas últimas possibilidades têm amplo suporte na literatura, como indicado nas referências (KARNA; JUNNONEN, 2017, PEGORARO; SAURIN; PAULA, 2010; PIAGENTINI; FAVARETO, 2014; ROSTAMI et al., 2015; SCHMALTZ, 2014;).

Com relação à solicitação de informações complementares para todas as modalidades de licenciamento, constatou-se que, em cerca de 50\% (Tabela 3) dos processos de licenciamento ambiental formalizados foram necessárias informações complementares para a continuidade da análise.

Tabela 3: Número de processos com solicitação de informações complementares em relação aos processos de licenciamento formalizados

\begin{tabular}{lcccc|}
\hline \multicolumn{1}{|c|}{ Tipo de licença } & $\begin{array}{c}\text { Processos } \\
\text { formalizados }\end{array}$ & $\begin{array}{c}\text { Processos com solicitação de } \\
\text { informações complementares }\end{array}$ \\
\hline Licença Prévia (LP) & 29 & 23 & $79,31 \%$ \\
Licença de Instalação (LI) & 66 & 63 & $95,45 \%$ \\
Licença Prévia concomitante a & 104 & 34 & $32,69 \%$ \\
Licença de Instalação (LP+LI) & 156 & 60 & $38,46 \%$ \\
Licença de Operação (LO) & 355 & 180 & $50,70 \%$ \\
Total & & & & \\
\hline
\end{tabular}

Fonte: Elaborado pela autora com base nas informações extraídas dos processos de licenciamento ambiental pesquisados

Verifica-se, portanto, um percentual muito alto de processos para os quais foram solicitadas informações complementares, principalmente com relação a processos de LP (79\%) e LP+LI (95\%). Estes números indicam que os processos não estão sendo protocolados com as informações consideradas mínimas necessárias para subsidiar as suas respectivas análises, o que pode ser interpretado como uma falha na formalização dos processos de licenciamento e nas informações e estudos ambientais que vêm sendo apresentados pelos empreendedores.

Visando quantificar o tempo de atraso que a solicitação de informações complementares pode ocasionar nos processos de licenciamento ambiental, foram analisados os prazos médios para obtenção das licenças, considerandose, separadamente, os processos de licenciamento nos quais houve ou não a solicitação de informações complementares (Tabela 4).

Tabela 4: Prazos médios para obtenção de licenças ambientais em processos com e sem solicitação de informações complementares

\begin{tabular}{l|c|c|}
\hline \multicolumn{1}{|c|}{ Tipo de licença } & $\begin{array}{c}\text { Prazo médio (em dias) para obtenção de } \\
\text { licenças para os quais houve solicitação } \\
\text { de informações complementares }\end{array}$ & $\begin{array}{c}\text { Prazo médio (em dias) para obtenção de } \\
\text { licenças para os quais não houve solicitação } \\
\text { de informações complementares }\end{array}$ \\
\hline $\begin{array}{l}\text { Licença Prévia (LP) } \\
\text { Licença de Instalação (LI) }\end{array}$ & 498 & 582 \\
Licença Prévia concomitante a \\
$\begin{array}{l}\text { Licença de Instalação (LP+LI) } \\
\text { Licença de Operação (LO) }\end{array}$
\end{tabular}

Fonte: Elaborado pela autora com base nas informações extraídas dos processos de licenciamento ambiental pesquisados 
Observa-se que os prazos para obtenção de licenças nos processos nos quais houve a solicitação de informações complementares são muito superiores aos prazos para os projetos em que a solicitação das informações complementares não foi necessária, exceto para a modalidade de Licença Prévia.

Analisando-se isoladamente as licenças concedidas para a modalidade de Licença Prévia no período considerado (2004-2015), observa-se que os casos nos quais não houve necessidade de informação complementar tiveram um tempo médio para a obtenção da licença menor do que no caso em que foram solicitadas essas informações. O dado está em contradição com as demais modalidades de licença. Como a amostra de casos de LP sem a solicitação de informação complementar é de apenas cinco processos, ela não permite identificar causas para esse comportamento.

No entanto, cabe levantar uma possibilidade. A Tabela 4 inclui apenas LP concedidas, uma amostra de 22 empreendimentos. Se fossem adicionados a essa amostra os empreendimentos cadastrados que ainda se encontram em fase de licenciamento, ou seja, cujas LP ainda não foram concedidas, o tempo médio para a obtenção da licença já seria maior no caso dos empreendimentos com solicitação de informações complementares. Isso quer dizer que a amostra considerada não está, nesse caso específico, refletindo o comportamento habitual das LP no universo de empreendimentos como um todo.

Com o objetivo de mapear as principais informações complementares solicitadas e identificar em quais aspectos as falhas estão ocorrendo com mais frequência, essas demandas foram classificadas e agrupadas por categorias, definidas a partir da estratificação dos dados, como indicado no Quadro 1. Essas categorias foram definidas com base na análise documental e qualitativa das informações complementares, agrupando-as pelos principais macrotemas ocorrentes, e são uma contribuição da pesquisa, na medida em que sistematizam os tipos de problemas identificados.

Quadro 1: Descrição das categorias das informações complementares

\begin{tabular}{|c|c|}
\hline Categoria & Descrição \\
\hline 1 & $\begin{array}{l}\text { Deficiências e informações relativas aos projetos de engenharia e caracterização do empreendimento: } \\
\text { solicitações relacionadas a projetos de engenharia e/ou informações relativas ao empreendimento que é objeto } \\
\text { do licenciamento, tais como vida útil, planos de lavra, planos de fogo, definições de acessos e infraestrutura, } \\
\text { áreas de empréstimo, áreas de disposição de material excedente, canteiros de obras, insumos, projetos ou } \\
\text { complementação dos projetos, informações relativas aos sistemas de controle ambiental, plantas, arranjos, novas } \\
\text { alternativas técnicas e/ou locacionais, solicitações em decorrência de alterações/adequações de projeto etc. }\end{array}$ \\
\hline 2 & $\begin{array}{l}\text { Deficiência e informações relativas aos diagnósticos ambientais, avaliação de impactos, medidas mitigadoras, } \\
\text { planos de controle ambiental, cumprimento de determinações anteriores (condicionantes, termos de compromisso, } \\
\text { termos de ajustamento de conduta, programas ambientais etc.) e outras informações de licenciamento. }\end{array}$ \\
\hline 3 & $\begin{array}{l}\text { Pendência de documentação legal: solicitações relativas à documentação legal necessária para a formalização e } \\
\text { análise de processos de licenciamento ambiental, a saber: anuências e autorizações emitidas por outros órgãos, } \\
\text { declarações de prefeitura, alvarás de funcionamento, procurações, publicações, documentações relativas ao } \\
\text { Departamento Nacional de Produção Mineral, anotações de responsabilidade técnica, documentos pessoais e } \\
\text { jurídicos, documentos autenticados, termos de responsabilidade, certidões de registro de imóvel e autorizações } \\
\text { de proprietários, comprovantes de pagamento de taxas de licenciamento e certidões negativas etc. }\end{array}$ \\
\hline 4 & $\begin{array}{l}\text { Problemas com Reserva Legal: solicitações relativas ao processo de regularização, relocação ou interferência } \\
\text { com áreas de Reserva Legal da propriedade na qual o empreendimento se insere. }\end{array}$ \\
\hline 5 & $\begin{array}{l}\text { Esclarecimentos com relação à supressão de vegetação e intervenção ambiental: informações relacionadas } \\
\text { à supressão de vegetação e intervenção em áreas de preservação permanente, definição de estágios } \\
\text { sucessionais, volumetrias, destinação do material lenhoso, plantas georreferenciadas, complementações e } \\
\text { esclarecimentos com relação ao diagnóstico de flora etc. }\end{array}$ \\
\hline 6 & $\begin{array}{l}\text { Esclarecimentos com relação a processos de outorga e uso de recurso hídrico: toda e qualquer informação } \\
\text { relacionada a outorga, fontes de água, balanço hídrico, mapeamento de nascentes e uso de recurso hídrico para } \\
\text { o empreendimento ou estruturas correlatas, incluindo os impactos relacionados a abastecimentos públicos. }\end{array}$ \\
\hline
\end{tabular}


Quadro 1: Continuação

\begin{tabular}{|c|l|}
\hline Categoria & \multicolumn{1}{c|}{ Descrição } \\
\hline 7 & Informações relativas à compensação ambiental. \\
\hline 8 & $\begin{array}{l}\text { Esclarecimentos e correções com relação à documentação protocolada, incoerências na documentação } \\
\text { apresentada e informações divergentes/contraditórias. }\end{array}$ \\
\hline 9 & $\begin{array}{l}\text { Solicitações não previsíveis: referem-se às solicitações inesperadas, podendo incluir solicitações em função } \\
\text { de mudança na legislação ambiental, reorientações de processos, cópias de documentos já protocolados, } \\
\text { informações já apresentadas, informações acerca de outras estruturas não vinculadas àquele determinado } \\
\text { processo de licenciamento, esclarecimentos aos questionamentos de outros órgãos ou organizações não } \\
\text { governamentais. }\end{array}$ \\
\hline 10 & $\begin{array}{l}\text { Estudos, projetos, relatórios e documentos específicos, que não fazem parte dos termos de referência para a } \\
\text { elaboração dos estudos ambientais. }\end{array}$ \\
\hline 11 & $\begin{array}{l}\text { Informações relativas ao patrimônio arqueológico, histórico, cultural e artístico, a saber: anuências, autorizações } \\
\text { e manifestações, complementação de levantamentos, documentos, relatórios ou evidências que comprovem a } \\
\text { preservação do patrimônio etc. }\end{array}$ \\
\hline
\end{tabular}

Fonte: Elaborado pela autora com base nas informações extraídas dos processos de licenciamento ambiental pesquisados

Com base nas categorias definidas, as 972 informações complementares mapeadas foram classificadas e os resultados estão apresentados na Tabela 5 e no Gráfico 1.

Tabela 5: Classificação das informações complementares em processos de licenciamento

\begin{tabular}{|c|c|c|c|}
\hline \multirow{2}{*}{\multicolumn{2}{|c|}{$\begin{array}{l}\text { Categorias } \\
\quad \text { № }\end{array}$}} & \multicolumn{2}{|c|}{$\begin{array}{l}\text { Total de informações complemen- } \\
\text { tares mapeadas para as categorias }\end{array}$} \\
\hline & & \multirow{2}{*}{$\begin{array}{r}\% \\
136\end{array}$} & \multirow[b]{2}{*}{$14 \%$} \\
\hline 1 & $\begin{array}{l}\text { Projetos de engenharia e caracterização } \\
\text { do empreendimento }\end{array}$ & & \\
\hline 2 & $\begin{array}{l}\text { Diagnóstico ambiental, avaliação } \\
\text { de impactos e medidas de controle } \\
\text { ambiental }\end{array}$ & 183 & $19 \%$ \\
\hline 3 & Documentação legal & 213 & $22 \%$ \\
\hline 4 & Reserva legal & 37 & $4 \%$ \\
\hline 5 & $\begin{array}{l}\text { Supressão de vegetação e intervenção } \\
\text { ambiental }\end{array}$ & 148 & $15 \%$ \\
\hline 6 & Outorga e uso de recurso hídrico & 48 & $5 \%$ \\
\hline 7 & Compensação ambiental & 27 & $3 \%$ \\
\hline 8 & $\begin{array}{l}\text { Informações divergentes/contraditórias } \\
\text { e incoerências }\end{array}$ & 35 & $4 \%$ \\
\hline 9 & Solicitações não previsíveis & 73 & $7 \%$ \\
\hline 10 & Estudos específicos & 39 & $4 \%$ \\
\hline 11 & $\begin{array}{l}\text { Patrimônio arqueológico, histórico, } \\
\text { cultural e artístico }\end{array}$ & 33 & $3 \%$ \\
\hline \multicolumn{2}{|c|}{ Total de informações complementares mapeadas } & 972 & $100 \%$ \\
\hline
\end{tabular}

Fonte: Elaborado pela autora com base nas informações extraídas dos processos de licenciamento ambiental pesquisados 
Gráfico 1: Classificação das informações complementares

\begin{tabular}{|l|l|l|}
\hline & Projetos de Engenharia e Caracterização do \\
& Empreendimento \\
& Diagnóstico Ambiental, Avaliação de \\
Impactose Medidas de Controle Ambiental \\
—
\end{tabular}

Fonte: Elaborado pela autora com base nas informações extraídas dos processos de licenciamento ambiental pesquisados

Percebe-se uma predominância de solicitações de informações complementares relacionadas à documentação legal (Categoria 3, 22\%), seguidas pela solicitação de informações relativas a diagnósticos ambientais, avaliação de impactos e medidas mitigadoras/planos de controle ambiental (Categoria 2,19\%), solicitação de esclarecimentos com relação à supressão de vegetação e intervenção ambiental (Categoria 5, 15\%) e solicitações em função de deficiências e informações relativas aos projetos de engenharia e caracterização do empreendimento (Categoria 1, 14\%).

Com base nesses resultados, pode-se observar que, além de uma notável falha identificada na atividade burocrática do processo de licenciamento, as demais podem estar relacionadas a indefinições de projeto, impactando, consequentemente, na elaboração dos estudos ambientais, na definição das áreas diretamente afetadas pelos empreendimentos e de suas respectivas medidas e nos planos de controle ambiental.

Visando verificar os principais aspectos aos quais essas informações estão relacionadas, algumas categorias foram subdivididas, de forma a possibilitar a identificação das predominâncias de solicitação referentes a cada categoria. Essa subdivisão também foi feita a partir da estratificação dos dados, agrupando os semelhantes nas subcategorias. Considerou-se pertinente a subdivisão das categorias 1, 2, 3 e 5, tendo em vista que elas apresentaram os maiores percentuais de informações complementares solicitadas. Não foi considerado necessário subdividir as demais categorias, tendo em vista que se tratam de categorias já bastante específicas e de pouca representatividade. A Tabela 6 apresenta os resultados para cada categoria, incluindo as subclassificações. 
Tabela 6: Subclassificação das informações complementares solicitadas para os processos de licenciamento

\begin{tabular}{|c|c|c|c|c|c|}
\hline \multicolumn{2}{|c|}{ Categorias } & \multicolumn{2}{|r|}{$\begin{array}{c}\text { Subcategorias № } \\
\% \text { em relação à categoria }\end{array}$} & \multicolumn{2}{|c|}{ Solicitações } \\
\hline \multirow{5}{*}{1} & \multirow{5}{*}{$\begin{array}{l}\text { Projetos de Engenharia } \\
\text { e Caracterização do } \\
\text { Empreendimento }\end{array}$} & 1.1 & Alternativas Técnicas e Locacionais & 29 & $21 \%$ \\
\hline & & 1.2 & Sistemas de Controle Ambiental & 12 & $9 \%$ \\
\hline & & 1.3 & $\begin{array}{l}\text { Complementação de documentos e informações em decorrência } \\
\text { de alterações/adequações de projeto }\end{array}$ & 22 & $16 \%$ \\
\hline & & 1.4 & Caracterização do empreendimento e demais projetos & 62 & $46 \%$ \\
\hline & & 1.5 & Informações específicas relativas à lavra & 11 & $8 \%$ \\
\hline \multirow{9}{*}{2} & \multirow{8}{*}{$\begin{array}{l}\text { Diagnóstico Ambiental, } \\
\text { Avaliação de Impactos } \\
\text { e Medidas de Controle } \\
\text { Ambiental }\end{array}$} & 2.1 & Esclarecimentos sobre propriedades de intervenção & 16 & $9 \%$ \\
\hline & & 2.2 & Programa de Educação Ambiental & 6 & $3 \%$ \\
\hline & & 2.3 & Impactos, medidas mitigadoras e planos de controle ambiental & 49 & $27 \%$ \\
\hline & & 2.4 & Informações sobre outros processos de licenciamento & 11 & $6 \%$ \\
\hline & & 2.5 & Informações relacionadas à Espeleologia & 27 & $15 \%$ \\
\hline & & 2.6 & $\begin{array}{l}\text { Informações relativas aos monitoramentos realizados (água e } \\
\text { efluentes, ar, ruído, vibração, fauna, etc.) }\end{array}$ & 21 & $12 \%$ \\
\hline & & 2.7 & $\begin{array}{l}\text { Esclarecimentos/complementações sobre o cumprimento de } \\
\text { condicionantes }\end{array}$ & 27 & $15 \%$ \\
\hline & & 2.8 & $\begin{array}{l}\text { Estudos não atendem/estão em desacordo com os Termos de } \\
\text { Referência }\end{array}$ & 7 & $4 \%$ \\
\hline & \multirow{13}{*}{ Documentação Legal } & 2.9 & Outras falhas no Diagnóstico Ambiental & 19 & $10 \%$ \\
\hline \multirow{12}{*}{3} & & 3.1 & Anuências de órgãos gestores de UC & 8 & $4 \%$ \\
\hline & & 3.2 & Declarações de Prefeitura e Alvarás de Funcionamento & 13 & $6 \%$ \\
\hline & & 3.3 & Anotações de Responsabilidade Técnica & 24 & $11 \%$ \\
\hline & & 3.4 & Documento de Registro de Imóvel & 26 & $12 \%$ \\
\hline & & 3.5 & $\begin{array}{l}\text { Reencaminhamento de documentos em função de assinaturas } \\
\text { em desacordo com a procuração }\end{array}$ & 37 & $18 \%$ \\
\hline & & 3.6 & $\begin{array}{l}\text { Documentação relativa ao Departamento Nacional de Produção } \\
\text { Mineral }\end{array}$ & 17 & $8 \%$ \\
\hline & & 3.7 & $\begin{array}{l}\text { Comprovantes de Pagamento de taxas e emolumentos de } \\
\text { licenciamento }\end{array}$ & 11 & $5 \%$ \\
\hline & & 3.8 & Documentos vencidos & 7 & $3 \%$ \\
\hline & & 3.9 & Documentos Pessoais dos procuradores & 7 & $3 \%$ \\
\hline & & 3.10 & Procurações & 14 & $7 \%$ \\
\hline & & 3.11 & Estatuto Social e Ata de Assembleia & 20 & $9 \%$ \\
\hline & & 3.12 & Outros & 29 & $14 \%$ \\
\hline \multirow[t]{2}{*}{4} & \multirow[t]{2}{*}{ Reserva Legal } & & & 37 & $100 \%$ \\
\hline & & 5.1 & $\begin{array}{l}\text { Licenças, Anuência e/ou Comprovações de formalização de } \\
\text { outros processos de supressão ou intervenção ambiental }\end{array}$ & 52 & $35 \%$ \\
\hline \multirow{5}{*}{5} & \multirow{5}{*}{$\begin{array}{l}\text { Supressão de } \\
\text { Vegetação e } \\
\text { Intervenção Ambiental }\end{array}$} & 5.2 & $\begin{array}{l}\text { Mapas em geral e informações acerca da área de intervenção/ } \\
\text { supressão vegetal/área diretamente afetada }\end{array}$ & 29 & $20 \%$ \\
\hline & & 5.3 & Destinação do material lenhoso & 9 & $6 \%$ \\
\hline & & 5.4 & Volumetria & 5 & $3 \%$ \\
\hline & & 5.5 & Cronograma de supressão & 21 & $14 \%$ \\
\hline & & 5.6 & Outros esclarecimentos & 32 & $22 \%$ \\
\hline 6 & \multicolumn{3}{|c|}{ Outorga e Uso de Recurso Hídrico } & 48 & $100 \%$ \\
\hline 7 & \multicolumn{3}{|l|}{ Compensação Ambiental } & 27 & $100 \%$ \\
\hline 8 & \multicolumn{3}{|c|}{ Informações divergentes/contraditórias e incoerências } & 35 & $100 \%$ \\
\hline 9 & \multicolumn{3}{|c|}{ Solicitações não previsíveis } & 73 & $100 \%$ \\
\hline 10 & \multicolumn{3}{|l|}{ Estudos Específicos } & 39 & $100 \%$ \\
\hline 11 & \multicolumn{3}{|c|}{ Patrimônio Arqueológico, Histórico, Cultural e Artístico } & 33 & $100 \%$ \\
\hline
\end{tabular}

Fonte: Elaborado pela autora com base nas informações extraídas dos processos de licenciamento ambiental pesquisados 
Analisando-se os resultados obtidos para a Categoria 1, verifica-se que há uma predominância de solicitação de informações complementares referentes à Caracterização do Empreendimento e demais projetos (46\%), seguidas pelas solicitações de informações relativas às Alternativas Técnicas e Locacionais (21\%) e de Complementação de documentos e informações em decorrência de alterações/adequações de projeto (16\%).

Esses resultados apontam para o fato de que as informações de projeto que estão sendo apresentadas na formalização dos processos de licenciamento geralmente são insuficientes para subsidiar suas respectivas análises. Além disso, cabem questionamentos em relação à maturidade dos projetos quando da sua submissão ao licenciamento, já que há grande incidência de informações complementares relativas às alternativas técnicas e locacionais e informações em decorrência de mudanças de projeto, que ocorreram ao longo do período de análise do processo por parte do órgão competente, ou seja, após a formalização do processo de licenciamento.

Esse resultado está em sintonia com os reportados na literatura. No caso de projetos de mineração, Romero e Andery (2008) identificaram projetos nos quais o desrespeito aos métodos estruturados de análise das soluções conceituais de projeto implicavam alterações de escopo, retrabalho e aumento de riscos. Santos (2015) comenta que a pressão para a execução dos empreendimentos leva a alterações de escopo e soluções de projeto, impactando no aumento de custos e prazos, o que poderia se aplicar ao caso dos processos específicos de licenciamento ambiental. As conclusões de Anantatmula (2015) e Lindhard e Larsen (2016) caminham na mesma direção.

$\mathrm{Na}$ Categoria 2, as falhas de maior representatividade ocorrem nas seguintes subcategorias: impactos, medidas mitigadoras e planos de controle ambiental (27\%), esclarecimentos/complementações sobre o cumprimento de condicionantes (15\%) e informações relacionadas à espeleologia (15\%). 0 tema espeleologia merece destaque, tendo em vista que se trata de um aspecto relativamente recente abordado nos processos de licenciamento e tem se tornado um fator dificultador.

Já na Categoria 3, os pontos predominantes são o novo encaminhamento de documentos em função de as assinaturas estarem em desacordo com a procuração (18\%), solicitações diversas (14\%), Certidões de Registro de Imóveis (12\%) e apresentações de Anotações de Responsabilidade Técnica (11\%).

Na categoria 5, 77\% das informações complementares solicitadas estão concentradas em apenas três subcategorias - Licenças e Autorizações para supressão de vegetação e intervenção em área de preservação permanente (35\%), outras informações/esclarecimentos em relação aos processos de supressão de vegetação ou intervenção em área de preservação permanente (22\%) e mapas em geral e informações acerca da área de intervenção/ supressão vegetal/área diretamente afetada (20\%).

Cabe levantar a hipótese de que a necessidade de complementação dos estudos ambientais, no que se refere aos impactos, medidas e planos de controle ambiental (Categoria 3) e a informações relativas à supressão de vegetação e intervenção em áreas de preservação permanente (Categoria 5), pode ser reflexo das indefinições de engenharia, tendo que vista que, sem um projeto bem definido e caracterizado, as avaliações ambientais, definições das áreas de intervenção e proposições de medidas de controle também passam a ser prejudicadas.

De qualquer forma, os resultados indicam que os maiores problemas associados ao atraso nos licenciamentos, decorrentes de solicitações de novas informações, perpassam não somente por questões burocráticas, como também pelo baixo nível de maturidade das soluções de projeto, seja em termos de distintas áreas da engenharia ou nos processos de análise ambiental, assim como na integração entre as duas atividades. 


\section{CONSIDERAÇÕES FINAIS}

Com base nos resultados apresentados, constatou-se que os prazos médios necessários para se licenciar um empreendimento no estado de Minas Gerais são bem maiores do que aqueles previstos na legislação ambiental vigente.

Verifica-se, portanto, que o processo de licenciamento ambiental constitui uma atividade crítica e que merece destaque no planejamento dos projetos, pois pode demandar um prazo significativo nos seus cronogramas, muito superior ao planejado.

O número de processos de licenciamento ambiental formalizados que exigiram informações complementares é expressivo, correspondendo a mais de $50 \%$ do total de processos protocolados. Observou-se uma alta representatividade de solicitação de informações relativas às categorias Documentação Legal, Diagnóstico Ambiental, Avaliação de Impactos e Medidas de Controle Ambiental, Supressão de Vegetação e Intervenção Ambiental e Projetos de Engenharia e Caracterização do Empreendimento, que, juntas, representam 70\% das informações solicitadas.

Esses resultados apontam para o fato de que os estudos de impacto ambiental, bem como as soluções conceituais de engenharia, não estão suficientemente desenvolvidos na etapa de licenciamento, o que implica mudanças em posturas estratégicas e operacionais durante a fase de concepção dos projetos de mineração.

Essa situação implica um prazo de, no mínimo, 60\% maior para a obtenção de licenças em processos com solicitação de informações complementares em relação àqueles nos quais não houve solicitação dessas informações, exceto para os processos de LP, cuja avaliação ficou prejudicada, considerando o alto número de processos de licenciamento formalizados com solicitação de informações complementares que ainda não tiveram suas respectivas licenças concedidas.

Portanto, a solicitação de informações complementares constitui um fator agravante, podendo ocasionar atrasos ainda maiores na análise dos processos de licenciamento, indicando a necessidade de adoção, pelos empreendedores, de ações e ferramentas que possibilitem minimizar a ocorrência de informações complementares, de forma a evitar que o processo de licenciamento ambiental seja um fator comprometedor nos cronogramas de implantação de projetos de mineração.

\section{REFERÊNCIAS}

AL-MOMANI, A. H. Construction delay: a quantitative analysis. International Journal of Project Management, Amsterdam, v. 18, p. $51-59,2000$

ANANTATMULA, V. Strategies for enhancing project performance. Journal of Management in Engineering, Reston, v. 3, n. 6, 2015.

BRASIL. Ministério do Meio Ambiente. Conselho Nacional do Meio Ambiente. Resolução no237, de 19 de dezembro de 1997. Dispõe sobre a revisão e complementação dos procedimentos e critérios utilizados para o licenciamento ambiental. Diário Oficial da União, Brasília, DF, n. 247, p. 30841-30843, 22 dez. 1997. Seção 1.

BROCKMANN, C.; KAIKONEN, K. Evaluating construction project complexity. In: CIB JOINT INTERNATIONAL SYMPOSIUM, 2012,
Rotterdam. Proceedings... Rotterdam, 2012. v. 1, p. 716-727.

COHEN, A.; ADOLFSON, L.; WOLFE, M. Environmental permitting for pipeline projects. In: JEONG, D.; PECHA, D. (Ed.). Pipelines 2011: a sound conduit for sharing solutions. Seattle: American Society of Civil Engineers, 2011. p. 1382-1392

DOLOI, $H$. et al. Analyzing factors affecting delays in Indian construction projects. International Journal of Project Management, Amsterdam, v. 30, p. 479489, 2012

EVANGELINOS, K. I.; OKU, M. Corporate environmental management and regulation of mining operations in the Cyclades, Greece. Journal of Cleaner Production, Amsterdam, v. 14, p. 262-270, 2006. 
KARNA, S.; JUNNONEN, J. Designers performance evaluation in construction projects. Engineering, Construction and Architectural Management, Bingley, v. 24, n. 1, p. 154-169, 2017.

LINDHARD, S.; LARSEN, J. Identifying the key process factors affecting project performance. Engineering, Construction and Architectural Management, Bingley, v. 22, n. 5, p. 657-673, 2016

MELO, H. C. Análise da priorização de atividades críticas em projetos lineares: estudo de caso em projetos ferroviários. 2014. 104p. Dissertação (Mestrado em Construção Civil) - Escola de Engenharia, Universidade Federal de Minas Gerais, Belo Horizonte, 2014

MORAES, F. R. G. Contribuição ao estudo da concepção de projetos de capital em megaempreendimentos. 2010. 196p. Dissertação (Mestrado em Construção Civil) - Escola de Engenharia, Universidade Federal de Minas Gerais, Belo Horizonte, 2010.

MOREIRA, A. M.; SILVA, R. S.; PALMA, M. A. M. Análise de gerenciamento de tempo aplicado a um projeto de petróleo. Revista de Gestão e Projetos, São Paulo, v. 1, n. 2, p. 128-146, 2010

PEGORARO, C.; SAURIN, T. A.; PAULA, I. C. Proposta de um procedimento para identificação e análise de requisitos ambientais no processo de projeto da construção civil: um estudo de caso. Gestão \& Tecnologia de Projetos, São Paulo, v. 5, n. 1, p. 79-108, 2010.

PIAGENTINI, P. M.; FAVARETO, A. S Instituições para regulação ambiental: o processo de licenciamento ambiental em quatro países produtores de hidroeletricidade. Desenvolvimento e Meio Ambiente, Curitiba, v. 30, p. 31-43, 2014.

PRADO FILHO, J.; SOUZA, M. O licenciamento ambiental da mineração no Quadrilátero Ferrífero de Minas Gerais: uma análise da implementação de medidas de controle ambiental formuladas em EIAs/ RIMAs. Engenharia Sanitária e Ambiental, Castelo, v. 9, n. 4, p. 343-349, 2004.

PROJECT MANAGEMENT INSTITUTE. Estudo de Benchmarking em Gerenciamento de Projetos Brasil 2010. Project Management Institute - Chapters Brasileiros. Rio de Janeiro, 2010. Disponível em: <https://goo.gl/YKw69v>. Acesso em: 25 set. 2017.
ROMERO, F.; ANDERY, P. Processos de desenvolvimento e validação de projetos de capital utilizando a metodologia FEL (Front End Loading). In: ENCONTRO NACIONAL DE TECNOLOGIA DO AMBIENTE CONSTRUÍDO, 12., 2008, Porto Alegre. Anais... Porto Alegre: Antac, 2008.

ROSTAMI, A. et al. Risk management in small and mediumenterprisesinthe UK construction industry. Engineering, Construction and Architectural Management, Hoboken, v. 22 , n. 1, p. 91-107, 2015.

SANTOS, H. P.; STARLING, C. M. D.; ANDERY, P. R. P. Um estudo sobre as causas de aumentos de custos e de prazos em obras de edificações públicas municipais. Ambiente Construído, Porto Alegre, v. 15, n. 4, p. 225-242, 2015.

SCHMALTZ, R. C. Evaluation of economic losses due to delays in environmental licensing process for Vale'siron ore projects. 2014. 84p. Final report Centre de Géosciences Mines ParisTech, Fontainebleau, France, 2014

SILVA NETO, J. C. A. Avaliação de maturidade no gerenciamento de projetos em uma empresa de mineração em Minas Gerais. 2011. 106p. Dissertação (Mestrado em Administração) - Fundação Mineira de Educação e Cultura, Faculdade de Ciências Empresariais, Belo Horizonte, 2011.

TERRIBILI FILHO, A. Os 8 porquês dos atrasos nos projetos. Meta Análise, 2011. Disponível em: <https://goo.gl/NQb2jY>. Acesso em: 5 out. 2017

Os cinco problemas mais frequentes nos projetos das organizações no Brasil: uma análise crítica. Revista de Gestão e Projetos, São Paulo, v. 4, n. 2, p. 213-237, 2013.

YIN, R. Case study research: design and methods. 5. ed. London: Sage, 2013.

YUGUE, R. T.; MAXIMIANO, A. C. A. Entendendo e gerenciando a complexidade de projetos. Revista de Gestão e Projetos, São Paulo, v. 4, n. 1, p. 1-22, 2013.

VAN GUSTEREN, L. A.; VAN LOON, P. Managing complex projects: proposed best practice attributes for managing complex projects and exploring their adoption in practice. In: INTERNATIONAL SCRI SYMPOSIUM, 3., 2006, Delft University, Netherlands. Proceedings... Netherlands: CIB, 2006
Priscilla Meireles de Oliveira priscillameireles@gmail.com

Paulo Roberto Pereira Andery pauloandery@gmail.com 
